\title{
FAKE NEWS, INFODEMIA E MÍDIAS SOCIAIS: DA HESITAÇÃO VACINAL ÀS BAIXAS COBERTURAS
}

\author{
Sheila Aparecida Ferreira Lachtim' \\ ORCID: 0000-0002-3323-5776
}

Alice Gomes Frugoli'

ORCID: 0000-0003-0000-7205

Carla Noel"

ORCID: 0000-0003-3495-8105

Mary Hellem Silva Fonseca"'

ORCID: 0000-0002-2830-5522

'Universidade Federal de Minas Gerais. Belo Horizonte, $\mathrm{BH}$.

"Sociedade Brasileira de Imunizações - SBIm. Petrópolis, RJ.

"'Universidade do Estado do Rio de Janeiro. Rio de Janeiro, RJ.

Autora Correspondente:

Sheila Aparecida Ferreira Lachtim

E-mail: sheila.massardi@gmail.com

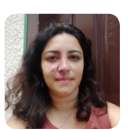

Como citar:

Lachtim SAF, Frugoli AG, Noel C, Fonseca MHS. Fake News, infodemia e mídias sociais: da hesitação vacinal às baixas coberturas. In: Silva TMR, Lima MG, (Orgs.). Estratégias de vacinação contra a COVID-19 no Brasil: capacitação de profissionais e discentes de enfermagem. Brasilia, DF: Editora ABen;2021. P 113-9. (Série enfermagem e pandemias, 6). https://doi.org/10.51234/aben.21.e08.c12

Revisora: Isabella Ballalai. Membro do Comitê de Saúde Escolar da Sociedade de Pediatria do Estado do Rio de Janeiro e do Comitê Técnico Assessor em Imunizações do Estado do Rio de Janeiro.

\section{INTRODUÇÃO}

A evolução da Internet e a acessibilidade cada vez maior às redes sociais permitem que todos possam criar e divulgar informações. Nesse processo de democratização da informação um termo chama atenção fake news - na tradução livre da expressão em inglês notícias falsas - tem gerado um impacto maior na sociedade nos últimos tempos $^{(1)}$. Para os autores, Allcott e Gentzkow ${ }^{(2)}$ o termo fake news é definido como um artigo noticioso produzido para ser intencionalmente falso e apto a ser verificado como tal, podendo, portanto, enganar os leitores que tiverem contato com esse material. Como exemplos desta definição têm-se as histórias fabricadas, notícias falsas e boatos, que não são novidades no meio comunicacional. Vale destacar, que esse tipo de fenômeno é registrado desde o Império Romano até os dias atuais, dando forças após o surgimento e popularização da Internet ${ }^{(3)}$. O fato é que as notícias falsas ou boatos fabricados com intencionalidade de desinformar tornam-se um grande problema quando são impulsionadas, por bots ou algoritmos que conseguem alcançar muitas pessoas e torna a disseminação desse conteúdo "viral"(4).

Nesse contexto, o termo que tem sido destaque na pandemia da COVID-19 é a "infodemia". O diretor-geral da OMS, Tedros Adhanom Ghebreyesus ${ }^{(5)}$ afirmou em seu discurso na Conferência de Segurança de Munique 2020 que "nós não estamos apenas lutando contra a pandemia, nós estamos lutando contra uma infodemia". De fato, o termo deriva de infodemiologia, cunhado por Gunther Eysenbach em 2002 e refere-se a informações sobre determinantes de saúde e políticas públicas nas populações ${ }^{(6)}$. No entanto, o termo infodemia está associado ao grande volume de informações de um determinado assunto, pouco confiável e com potencial para se multiplicar exponencialmente. Nessa situação, surgem rumores e desinformação, além da manipulação de informações com intenção duvidosa. Na era da informação, esse fenômeno é amplificado pelas 
redes sociais e se alastra mais rapidamente, como é o caso das informações associadas ao vírus que causa a COVID-19(7).

As fake news são disseminadas pelas mídias sociais possibilitando diversos compartilhamentos produzindo uma rede com conteúdo e pseudo-informações. Assim como um "vírus" têm potencial para contaminar rapidamente a comunicação e influenciar no comportamento da sociedade que recebe as informações. As informações publicadas por autoridades técnicas no campo da saúde podem não ter a mesma rapidez e fluidez na veiculação da mensagem, ou seja, em tempos de avanços tecnológicos, estas notícias falsas são veiculadas nas redes sociais e propagadas de forma mais rápida do que as notícias de autoridades técnicas que requerem embasamento científico e teórico para serem disseminadas ${ }^{(8)}$.

Outro ponto importante, é que o excesso de informação sendo ela verdadeira ou falsa dificulta na orientação das pessoas por não saberem qual informação seguir como verdade. Pode inclusive prejudicar a tomada de decisão por gestores e profissionais da saúde, especialmente quando não há tempo hábil para avaliar as evidências disponíveis. A sobrecarga com o bombardeamento constante de informações possibilitada por diversos meios e mídias (como televisão, rádio, computador, tablets, smartphones, jornais impressos ou eletrônicos, blogs, mídias sociais, aplicativos de conversas) pode possibilitar que as pessoas se tornem ansiosas, deprimidas, ou até mesmo exauridas e incapazes de responder às demandas que se apresentam ${ }^{(7)}$.

\section{AS REPERCUSSÕES DAS FAKE NEWS NA PANDEMIA E A IMUNIZAÇÃO CONTRA COVID-19}

Nesse momento pandêmico, observa-se a disseminação de informações falsas relacionadas à COVID-19, como as notícias que afirmam a inexistência de casos de COVID-19, inclusive com imagens de leitos hospitalares desocupados, e aquelas que relatam métodos caseiros para a prevenção do contágio pelo coronavírus, tratamentos sem comprovação científica de eficácia, e teorias conspiratórias que atribuem a pandemia a uma estratégia política, com posicionamentos contrários às medidas de distanciamento social necessárias à contenção da propagação da doença ${ }^{(7)}$.

No contexto das imunizações, observa-se, conforme reportagem da Pesquisa Fapesp publicada em agosto de 2018, a associação entre as quedas da cobertura vacinal e a influência das fake news, que circulam nas redes sociais, e de uma incipiente ação de grupos contrários à imunização, também conhecidos como movimentos antivacinação. De acordo com a Revista, na Europa e nos Estados Unidos os grupos que não aderem à vacinação por alegarem razões religiosas e filosóficas ou por se embasarem em informações inverídicas são mais comuns ${ }^{(3)}$.

O Brasil possui um dos maiores programas de imunização do mundo, conhecido por sua alta cobertura vacinal. A atuação do Programa Nacional de Imunizações - PNI está direcionada para o alcance do Quarto Objetivo de Desenvolvimento do Milênio (ODM) - reduzir a mortalidade na infância ${ }^{(9-10)}$, diminuindo significativamente a incidência e mortes por doenças imunopreveníveis tais como o sarampo, poliomielite e coqueluche ${ }^{(11)}$. Essas ações garantiram ao Brasil, em 2016, o certificado de eliminação da circulação do vírus do sarampo pela Organização Mundial da Saúde - OMS(12).

No entanto, apenas três anos depois, em 2019 atestou-se o aparecimento de novos casos da doença, frisando que não havia registro de casos desde $2000^{(13)}$, o que culminou na perda do certificado internacional(14) e impôs ao país um novo desafio de saúde pública. A situação não se restringe somente ao sarampo. Nos últimos anos, o Brasil tem enfrentado o ressurgimento de doenças infectocontagiosas na população, como a febre amarela(15).

Entre os diversos fatores que estão envolvidos no reaparecimento de doenças já eliminadas, destaca-se a queda da cobertura vacinal que estima o nível de proteção da população infantil contra doenças imunopreveníveis ${ }^{(16)}$, sendo que as quedas a partir de 2013, com intensificação em $2016^{(15)}$, sinalizam um problema para a imunização coletiva do PNI. Coberturas historicamente altas, como a da vacina da poliomielite, estiveram 
abaixo da meta nos últimos anos ${ }^{(11)}$. No caso do sarampo, por exemplo, um dos motivos para a volta da circulação está na queda da cobertura vacinal em $20 \%^{(14)}$.

Muitas questões estão relacionadas à queda da cobertura vacinal, entre elas: enfraquecimento do Sistema Único de Saúde (SUS);aspectos técnicos como a implantação do novo sistema de informação de imunização;aspectos sociais e culturais que afetam a aceitação da vacinação;e os movimentos antivacinas. Esses elementos, entre outros, constituem o processo complexo da hesitação vacinal, que variam ao longo do tempo e podem apresentar especificidades em cada diferente contexto ${ }^{(17)}$.

As quedas da cobertura vacinal são um problema mundial e têm sido amplamente investigadas. Em 2014, o Grupo Consultivo Estratégico de Especialistas (SAGE) em Imunização da Organização Mundial da Saúde (OMS) revisou definições e modelos e estabeleceu o termo "hesitação vacinal" como o atraso na aceitação ou recusa da vacinação, apesar da disponibilidade de serviços de vacinação. Ou seja, se o indivíduo decide pela não vacinação ou cogita a hipótese, ele está hesitante. A hesitação vacinal coloca em risco a imunização de rebanho, trazendo consequências à saúde pública ${ }^{(18)}$.

Destaca-se aqui dois modelos desenvolvidos pela OMS para elucidar a hesitação vacinal, o Modelo dos 3 C's e a Matriz de Determinantes. O modelo dos 3 C's os descrevem em três categorias: confiança, complacência e conveniência (Quadro 1), e não se aplica a casos em que as taxas de vacinação são baixas por causa da pequena disponibilidade, oferta ou acesso às vacinas, programa de vacinação insatisfatório, comunicação, etc. Já a matriz de determinantes de hesitação vacinal também propõe três categorias, mas em outro viés: influência de contexto, influência individual e de grupo, e influência específica da vacina/vacinação (Quadro 2) ${ }^{(18)}$.

Quadro 1 - Modelo dos 3 C's da hesitação vacinal, Organização Mundial de Saúde, 2014

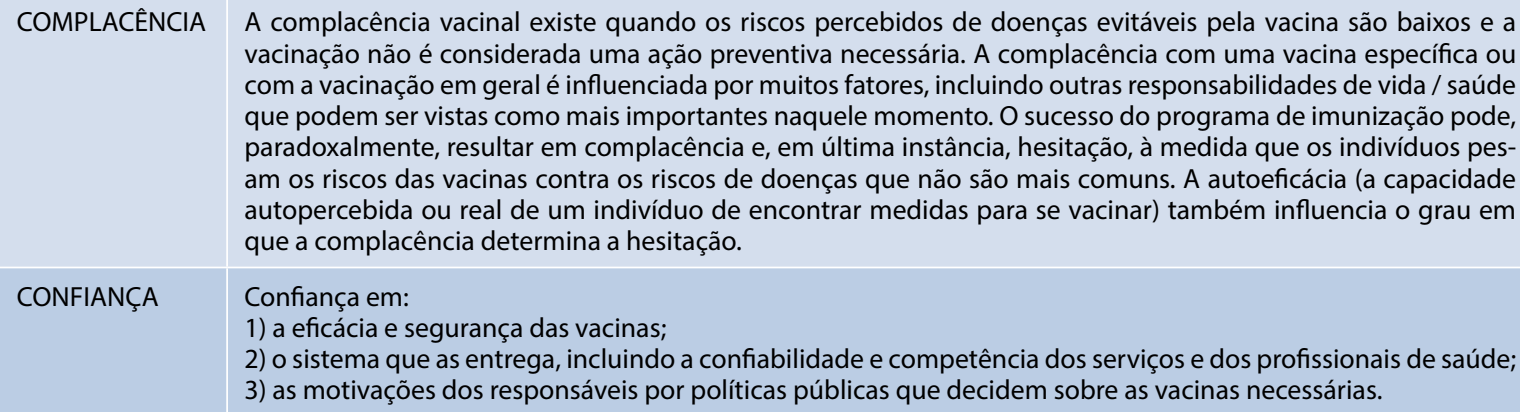
vacinação não é considerada uma ação preventiva necessária. A complacência com uma vacina específica ou com a vacinação em geral é influenciada por muitos fatores, incluindo outras responsabilidades de vida / saúde que podem ser vistas como mais importantes naquele momento. $O$ sucesso do programa de imunização pode, paradoxalmente, resultar em complacência e, em última instância, hesitação, à medida que os indivíduos pesam os riscos das vacinas contra os riscos de doenças que não são mais comuns. A autoeficácia (a capacidade autopercebida ou real de um indivíduo de encontrar medidas para se vacinar) também influencia o grau em que a complacência determina a hesitação.

CONFIANÇA Confiança em:

1) a eficácia e segurança das vacinas:

2) o sistema que as entrega, incluindo a confiabilidade e competência dos serviços e dos profissionais de saúde;

3) as motivações dos responsáveis por políticas públicas que decidem sobre as vacinas necessárias.

CONVENIÊNCIA Medida por disponibilidade física, acessibilidade e disposição a pagar pela vacinação, acessibilidade geográfica, capacidade de compreensão (idioma e conhecimento em saúde), apelo dos serviços de imunização, a qualidade do serviço (real e/ou percebido), grau em que os serviços de vacinação são prestados em um momento e local, e em um contexto cultural que seja conveniente e confortável.

Fonte: Fonte: Adaptado $\mathrm{WHO}^{(18)}$ (tradução livre pelos autores)

Quadro 2 - Matriz de determinantes de hesitação vacinal, Organização Mundial de Saúde, 2014
INFLUÊNCIA DE CONTEXTO
Influências decorrentes de fatores históricos, socioculturais, ambientais, do sistema de saúde /institucionais, econômicos ou políticos.

a. Comunicação e mídia;

b. Líderes influentes, mídia sobre programa de imunização, políticas anti e pró-vacinação;

c. Influências históricas;

d. Religião/cultura/gênero/nível socioeconômico;

e. Política/políticas;

f. Barreiras geográficas;

g. Percepção sobre a indústria farmacêutica. 
Continuação do Quadro 2

\begin{tabular}{|c|c|}
\hline $\begin{array}{l}\text { INFLUÊNCIA INDIVIDUAL } \\
\text { E DE GRUPO } \\
\text { Influências decorrentes } \\
\text { de percepções pessoais } \\
\text { sobre a vacina ou de } \\
\text { influências do ambiente } \\
\text { social/ de semelhantes. }\end{array}$ & $\begin{array}{l}\text { a. Experiência de vacinação pessoal, da família ou membros da comunidade, incluindo dor; } \\
\text { b. Crenças, atitudes sobre saúde e prevenção; } \\
\text { c. Conhecimento/consciência; } \\
\text { d. Confiança no sistema de saúde e servidores de saúde, experiência pessoal; } \\
\text { e. Risco/benefício (percebido/heurístico); } \\
\text { f. Imunização como norma social vs. desnecessário/prejudicial. }\end{array}$ \\
\hline $\begin{array}{l}\text { INFLUÊNCIA ESPECÍFICA } \\
\text { DE VACINAS/VACINAÇÃO } \\
\text { Diretamente relacionada } \\
\text { à vacinas ou vacinação. }\end{array}$ & $\begin{array}{l}\text { a. Risco/benefício (epidemiológico e por evidências científicas); } \\
\text { b. Introdução de uma nova vacina ou nova fórmula, ou uma nova recomendação para uma vacina existente; } \\
\text { c. Modo de administração; } \\
\text { d. Projeto do programa de vacinação/modo de entrega (programa de rotina ou campanhas de vacinação } \\
\text { em massa); } \\
\text { e. Confiabilidade e/ou fonte de fornecimento de vacina, e/ou equipamento de vacinação; } \\
\text { f. Calendário de vacinação; } \\
\text { g. Custos; } \\
\text { h. A intensidade da recomendação e/ou base de conhecimento, e/ou atitude de profissionais de saúde. }\end{array}$ \\
\hline
\end{tabular}

Ambos os modelos estabelecidos pela OMS contemplam a confiança da população nos aspectos que permeiam a imunização. Um estudo recente demonstrou que fake news sobre imunização questionam, entre outros fatores, a eficácia e segurança das vacinas. Além disso, agravada pela desinformação, a veiculação de informações falsas interfere diretamente na confiança do indivíduo e, potencialmente, produzem hesitação vacinal ${ }^{(19)}$.

A confiança nos imunobiológicos está entre as razões mais comuns para a hesitação vacinal mais diretamente no que se refere a confiança nas vacinas, eficácia/segurança da vacina e preocupação com eventos adversos das mesmas (15). Além desses fatores aparecem também o desabastecimento de imunobiológicos, atribuído a dificuldades na entrega de vacinas internacionais / insumos e a capacidade de produção dos laboratórios ${ }^{(20)}$.

A manutenção de altas coberturas vacinais nos padrões de números estimados e a homogeneidade proporcionam a efetividade das vacinas no âmbito individual e coletivo, como um bom indicador de saúde pública ${ }^{(21)}$. Nesse sentido, a OMS recomenda pelo menos $95 \%$ de cobertura vacinal para manutenção da erradicação, eliminação ou controle de doenças imunopreveníveis ${ }^{(22)}$.

Foi por esse contexto que, a Organização Mundial da Saúde e o Fundo das Nações Unidas apontaram a hesitação em vacinar como um problema mundial. Estudos indicaram que uma criança nascida tem a probabilidade inferior a $20 \%$ de receber todas as vacinas recomendadas até os 5 anos de idade. Isto obtém reflexo no ano de 2019, quando quase 14 milhões de crianças perderam a oportunidade de receber as vacinas oferecidas para a faixa etária(23).

\section{FERRAMENTAS QUE AUXILIAM OS PROFISSIONAIS DE SAÚDE PARA COMBATER AS FAKE NEWS EM IMUNIZAÇÃO PARA COVID-19}

Obviamente que para combater as fake news em imunizações é necessária uma ampla discussão na sociedade, localizando essa problemática no tempo e espaço. A imersão na Sociedade da Informação, implica em informações muito rápidas e em grande volume tornando, por vezes, difícil a tarefa de reconhecer notícias vinculadas com conteúdos falsos. Nesse sentido, é importante o desenvolvimento de políticas regulatórias por parte do Estado e por parte das empresas de mídias sociais, uma vez que a maior parte do compartiIhamento se dá nessas plataformas ${ }^{(24)}$. No entanto, há uma linha tênue entre a regulação e a censura. Nesse sentido, a censura é algo exercido antes da publicação de qualquer conteúdo, mesmo que não o altere ou proíba. Regulação é o estabelecimento de regras de funcionamento de uma área(25).

Dentre as ações que são possíveis estão o controle dos algoritmos e bots muito úteis para marketing de produtos, mas que porém permitiram a massificação das fake news. Empresas como Facebook buscaram parcerias com agências de fact checking certificadas pela Agência Internacional de Checagem de Fatos para 
coibir o alcance de fake news vinculadas em seu APP. Recentemente, o WhatsApp diminui para cinco a possibilidade de compartilhamentos entre pessoas ou grupos a fim de dificultar o compartilhamento em massa. Por outro lado, há pesquisadores desenvolvendo, por meio de inteligência artificial, detectores de fake news que possam ser utilizados preservando a privacidade dos usuários dos APPs.

Há diversos projetos de lei sendo discutidos na Câmara dos Deputados, que vão desde mudanças na Constituição Federal e criminalização de impulsionadores de fake news até ações de alfabetização digital em escolas, é um leque amplo de propostas, e exatamente por isso, requer um amplo debate social.Vale ressaltar que países como Reino Unido e Indonésia apoiam alfabetização digital, enquanto países como Canadá, Finlândia e Austrália reestruturaram os currículos escolares e integraram a alfabetização digital como conteúdo nas escolas ${ }^{(26)}$.

A pergunta que fica é: como podemos reconhecer uma notícia falsa? As fake news têm impacto na assistência e como profissionais da saúde é importante reconhecê-las, uma vez que se o profissional de saúde compartilha o conteúdo falso, ele o endossa. Uma das possibilidades é utilizar um dos diversos sites de checagem, tais como boatos.org, aos fatos, agência Lupa, e-farsas, entre outros. Várias agências de checagem da América Latina se reuniram num consórcio e construíram um site especifico para a pandemia do COVID-19, checando notícias que circulam por toda a região: https://chequeado.com/latamcoronavirusportugues/.

Caso a notícia ainda não tenha sido checada é importante que os profissionais tenham ferramentas para compreender se a notícia é ou não falsa. Não há receitas prontas, porém é possível apontar alguns cuidados ${ }^{(27)}$ :

1-Desconfie de informações que comprovem sua visão de mundo;

2-Não divulgue informações se não tem certeza que é verdadeira;

3-Se de fato, a informação for urgente, importante e fundamentada, em instantes estará em vários veículos de informação;

4-A notícia deve ter minimamente informações sobre data, autor e fonte dos dados vinculados;

5-Conheça o histórico do veículo de informação;

6-Verifique o nome do site e data;

7-Confira a relação da manchete com o texto das matérias que você lê na Internet.

Para além de reconhecer as fake news, principalmente relacionadas com a saúde, é possível interferir no seu ciclo de compartilhamento com boas práticas do uso das plataformas, aplicativos e mídias sociais (Figura 1).

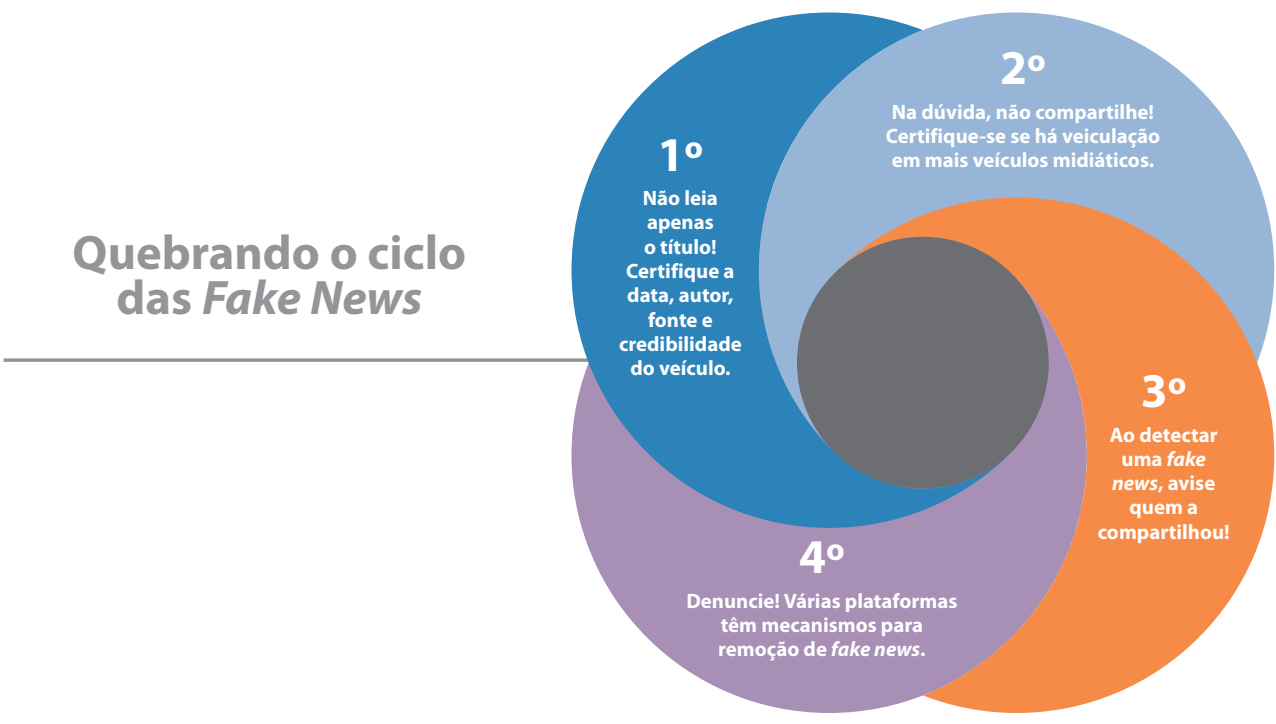

Figura 1- Ciclo de boas práticas nas mídias sociais.

Fonte: produção própria baseada In: Alburqueque ${ }^{28}$. 


\section{CONCLUSÃO}

Para que o PNI retome o êxito em suas campanhas e na vacinação de rotina é importante considerar entre outros fatores, a influência das fake news que circulam nas redes sociais, a resistência diante da possibilidade de ser vacinado - muitas vezes motivado por desinformações já é um problema real -, os movimentos antivacinas também são crescentes e são protagonistas na propagação de informações de saúde, principalmente relacionadas a imunização, incorretas e compartilhadas principalmente na Internet e redes sociais. Nesse sentido, é necessária uma ampla discussão com a sociedade a fim de coibir grandes impulsionadores de fake news e manter a credibilidade no PNI, no intuito de combater a hesitação vacinal e melhorar as coberturas vacinais e, por conseguinte, a imunidade coletiva.

\section{REFERÊNCIAS}

1. Ministério da Saúde (BR). O perigo das Fake News para nossa saúde. Blog da Saúde [Internet]. Brasília: MS; 2018 [cited 2021 Aug 12]. Available from: http://www.blog.saude.gov.br/index.php/ servicos/53515-o-perigo-das-fake-news-para-nossa-saude

2. Allcott H, Gentzoknow M. Social media and fake news in the 2016 election. J Econ Perspect. 2017;31(2):211-36 https://doi. org/10.1257/jep.31.2.211

3. Monari ACP, Bertolli Filho C. Saúde sem Fake News: estudo e caracterização das informações falsas divulgadas no canal de informação e checagem de Fake News do ministério da saúde. Rev Mídia Cotidiano. 2019;13(1). https://doi.org/10.22409/ ppgmc.v13i1.27618

4. Nemer D. Desinformação no contexto da pandemia do Coronavírus (COVID-19). AtoZ: novas práticas em informação e conhecimento. AtoZ Rev Eletron. 2020;9(2):113-6. https://doi.org/10.5380/atoz.v9i2.77227

5. Eysenbach G. How to fight an infodemic: the four pillars of infodemic management. J Med Internet Res. 2020;22(6):e21820. https://doi.org/10.2196/21820

6. Mavragani A. Infodemiology and infoveillance: scoping review. J Med Internet Res. 2020;22(4):e16206. https://doi. org/10.2196/16206

7. Garcia LP, Duarte E. Infodemia: excesso de quantidade em detrimento da qualidade das informações sobre a COVID-19. Epidemiol Serv Saúde. 2020;29(4). https://doi.org/10.1590/S1679-49742020000400019

8. Neto M, Gomes TO, Porto FR, Rafael RMR, Fonseca MHS, Nascimento J. Fake news no cenário da pandemia de Covid-19. Cogitare Enferm, 2020;25:e72627.https://doi.org/10.5380/ce.v25i0.72627.

9. Ministério da Saúde (BR). Programa Nacional de Imunizações: 30 anos [Internet]. Brasília: MS; 2003 [cited 2021 Aug 12]. Available from: https://bvsms.saude.gov.br/bvs/publicacoes/livro_30_anos_pni.pdf

10. Ministério da Saúde (BR). I Conferência Internacional de Monitoramento dos Objetivos de Desenvolvimento do Milênio no Setor Saúde: Rumo ao Alcance das Metas de 2015 [Internet]. Brasília; 2015[cited 2021 Aug 12]. Available from: http:// bvsms.saude.gov.br/bvs/publicacoes/conferencia_internacional_desenvolvimento_objetivo.pdf

11. Ministério da Saúde (BR). Coberturas vacinais no Brasil Período: 2010 - 2014 [Internet]. Brasília: MS; 2015. [cited 2021 Aug 12]. Available from: https://portalarquivos2.saude.gov.br/images/pdf/2017/agosto/17/AACOBERTURAS-VACINAIS-NOBRASIL---2010-2014.pdf

12. Ministério da Saúde (BR). Brasil recebe certificado de eliminação do sarampo [Internet]. Brasília; 2018[cited 2021 Aug 12]. Available from: https://www.saude.gov.br/noticias/ agencia-saude/25846-brasil-recebe-certificado-de-eliminacao-do-sarampo.

13. Ministério da Saúde (BR). Informe n 35: Situação do Sarampo no Brasil-2019[Internet]. Brasília; 2019[cited 2021 Aug 12]. 18p. Available from: https://portalarquivos2.saude.gov.br/images/pdf/2019/janeiro/10/Informe-Sarampon35-9jan19gab.pdf

14. Medeiros EAS. Entendendo o ressurgimento e o controle do sarampo no Brasil. Acta Paul Enferm. 2020;33(1). https://doi. org/10.37689/acta-ape/2020EDT0001 
15. Brown AL, Sperandio M, Turssi CP, Leite RMA, Berton VF, Succi MR, et al. Vaccine confidence and hesitancy in Brazil. Cad Saúde Pública[Internet]. 2018[cited 2021 Aug 12];34(9):1-11. Available from: https://www.scielo.br/pdf/csp/v34n9/16784464-csp-34-09-e00011618.pdf

16. Ministério da Saúde (BR). Cobertura vacinal: F.13 [Internet]. Brasília; 2008[cited 2021 Aug 12]. Available from: http://fichas. ripsa.org.br/2008/f-13/

17. Sato APS. Qual a importância da hesitação vacinal na queda das coberturas vacinais no Brasil? Rev Saude Publica. 2018;52:96:1-9. https://doi.org/10.11606/S1518-8787.2018052001199

18. World Health Organization. Report of the Sage Working Group on vaccine hesitancy [Internet]. Geneva: WHO; 2014[cited 2021 Aug 12]. Available from: https://www.who.int/immunization/sage/meetings/2014/october/1_Report_WORKING_ GROUP_vaccine_hesitancy_final.pdf

19. Frugoli AG, Prado RS, Silva TRM, Matozinhos FP, Trape CA, Lachtim SAF. Fake news sobre vacinas: uma análise sob o modelo dos 3C's da Organização Mundial de Saúde. Rev Esc Enferm USP. 2021;55:e03736. https://doi.org/10.1590/ S1980-220X2020028303736

20. Fonseca KR, Buenafuente SMF. Análise das coberturas vacinais de crianças menores de um ano em Roraima, $2013-2017$. Epidemiol Serv Saúde. 2021;30(2). https://doi.org/10.1590/S1679-49742021000200010

21. Silva ABS, Araújo ACM, Santos MCS, Andrade MS, Mendonça RM. Indicadores de cobertura vacinal para classificação de risco de doenças imunopreveníveis. Rev Bras Promoç Saúde. 2019;32:9285. https://doi.org/10.5020/18061230.2019.9285

22. Braz RM Domingues CMAS, Teixeira MAS, Luna EJA. Classificação de risco de transmissão de doenças imunopreveníveis a partir de indicadores de coberturas vacinais nos municípios brasileiros. Epidemiol Serv Saúde. 2016;25(4)745-54. https:// doi.org/10.5123/S1679-49742016000400008

23. Castro A. Impacto das fake news nas coberturas vacinais [Internet]. Fiocruz. Ministério da Saúde. Rio de Janeiro, 2020[cited 2021 Aug 12]. Available from: https://www.bio.fiocruz.br/index.php/br/ noticias/2052-impacto-das-fake-news-nas-coberturas-vacinais

24. Castells M. A era da informação: economia, sociedade e cultura. In: A Sociedade em rede. São Paulo: Paz e Terra, 2000. v. 1. https://doi.org/10.17231/comsoc.5(2004).1256

25. Messagi Jr M. Sem liberdade não existe jornalismo. In: Guilherme Carvalho. (Org.). A ética no jornalismo brasileiro: conceitos, práticas e normas. Curitiba: InterSaberes; 2019;1:322-351.

26. Digital Future Society. Dealing with disinformation: strategies for digital citizen empowerment [Internet]. Barcelona: 2020. [cited 2021 Aug 12]. Available from: https://itsrio.org/wp-content/uploads/2020/07/Informe-C\%C3\%B3mo-combatir-ladesinformaci\%C3\%B3n.pdf

27. Sorj B, Cruz FB, Santos MW, Ribeiro MM, Ortellado P. Sobrevivendo nas redes: guia do cidadão. Coleção ensaios democracia digital [Internet]. São Paulo, 2018. [cited 2021 Aug 12]. Available from: http://www.plataformademocratica.org/Arquivos/ Sobrevivendo_nas_redes.pdf

28. Universidade Federal de Pernambuco. Manual de enfrentamento das fake News [Internet]. UFPE: Recife, 2020 [cited 2021 Aug 12]. Available from: https://sites.ufpe.br/rpf/wp-content/uploads/sites/43/2020/05/Manual-de-enfrentamento-a-fakenews.pdf 